\title{
Athabasca University Reduces ICT Carbon Footprint
}

\author{
Brian Stewart and Anshuman Khare
}

\begin{abstract}
This paper discusses a plan that has been developed to move Athabasca University (AU) forward in its objective of reducing Greenhouse Gas (GHG) emissions. Specifically the plan will reduce Information and Communication Technology (ICT) related carbon emissions by a minimum of 30 percent by 2012 . By achieving its goals, it will also move AU closer to compliance with the American Colleges and Universities Presidents' Commitment to Climate Change (ACUPCC).
\end{abstract}

Index Terms - American Colleges and Universities Presidents' Commitment to Climate Change (ACUPCC), distance education post-secondary institution, ICT related carbon emissions, ACUPCC Implementation Guidelines, procurement policies, electronic waste reduction.

\section{INTRODUCTION}

Athabasca University is Canada's Open University. As a distance education institution, the environmental footprint of the University is rather small compared to a brick-and-mortar institution. However, the University relates to the global concerns related to carbon emissions and climate change. In its endeavor to make a difference it has taken an active role along with some other North American institutions to further reduce its carbon impact.

This paper discusses a plan that has been developed to move Athabasca University (AU) forward in its objective of reducing Greenhouse Gas (GHG) emissions. Specifically the plan will reduce Information and Communication Technology (ICT) related carbon emissions by a minimum of 30 percent by 2012. By achieving its goals, it will also move AU closer to compliance with the American Colleges and Universities Presidents' Commitment to Climate Change (ACUPCC) [1].

The goals and recommendations outlined in this paper have been constructed on the basis of their achievability, their applicability and their advancement within the AU context. They take into account existing plans and capabilities, and are cognizant of the resources and organizational dynamics currently operating within the institution.

The plan follows the format of the ACUPCC Implementation Guidelines [2] and breaks the recommendations into the following sections:

Brian Stewart is Vice President, Information Technology \& Chief Information Officer at Athabasca University, 1 University Drive, Athabasca AB T9S 3A3 CANADA (email: brains@athabascau.ca)

Anshuman Khare is Professor at Athabasca University, 301-22 Sir Winston Churchill Avenue, St. Albert AB T8N 1B4, CANADA (corresponding author Phone: +1-780-4187533; email: anshuman@athabascau.ca)
1. Establish an Institutional Structure

2. Measure Greenhouse Gas Emissions

3. Tangible actions

4. Climate Action Plan

5. Reporting Requirements

Each section of this paper begins with a restatement of the ACUPCC Implementation Guideline recommendation and proceeds to outline the proposed objectives and actions of Athabasca University.

\section{ESTABLISH AN INSTITUTIONAL STRUCTURE}

The first step in the ACUPCC implementation guideline (after signing the declaration) is to within two months of the implementation start date establish a committee or institutional structure to guide the development and implementation of the school's plan. This must include faculty, staff and students.

Athabasca University has begun the task of forming an institutional Committee in concert with ACUPCC. One of the key tasks of this committee will be to undertake a communications program to raise the overall level of awareness of the importance of Climate Change to everyday campus activities. This will include a Green ICT site for the sharing of knowledge regarding AU's initiatives. The involvement from the Information Technology Services (ITS) groups will be to have representation, through the CIO, on the institutional committee. In addition, the ITS Computing Governance Committee will act as the Green Computing Committee. This committee's mandate is to provide guidance to the University's Executive Group on computing infrastructure initiatives and to act as the institution's subject matter experts in such matters. It forms part of the three committee governance structure that also includes ITS Learning and Research and ITS Administrative committees.

Objective 1.0: The ITS Computing Committee will act as the Green ICT governance committee: Having one of the three already established ITS governance committees of Athabasca University retain a focus on forwarding the Green ICT agenda will ensure that all infrastructure projects have given due consideration to climate impacts. In addition, the committee can provide leadership for the advancement of Green ICT initiatives and thereby influence all ICT-related activities.

\section{Measure GreEnHOUSE Gas EMISSIONS}

The ACUPCC guidelines recommend that within one year of their implementation start date and annually thereafter, participating colleges and universities must complete an inventory and publicly report on their greenhouse gas emissions using established protocols outlined in this document. 
To address this issue, Athabasca University has begun to use the recently developed ICT Footprint tool [3], published by the Joint Information System Committee (JISC) to measure its ICT related GHG emissions. The JISC emissions calculator provides a sufficiently granular level of detail to facilitate effective reporting while also allowing improved ability to initiate action in ICT related activities. The tool can be customized to reflect local energy cost and emissions outputs, thereby providing a more accurate profile. In addition the results can be published on the Green ICT site.

The full inventory of ICT activities has been started. The initial calculation is seen as a first step, the emission values, in all but a few places, were computed using the default settings in the footprint tool. The $\mathrm{CO}_{2}$ emission values are based on an average of energy generation sources. While a little imprecise the inventory is accurate in the broader analysis and provides a very useful baseline for planning and comparison of Green ITC initiatives. As the tool is updated, previous values can be adjusted to show more precise readings, thereby providing a consistent trend, which is essential to the evaluation of reduction activities.

Objective 2.0: Independently measure data centre power usage: Energy flow to the datacentre needs to be independently metered to provide a distinct data set that can provide energy usage patterns for the datacentre. In addition, the data set can provide correlative information to the energy usage model, enabling verification of predicated and estimated values.

The installation of independent power line meters would be disruptive to service as it would require downtime to introduce them into the flow. While this remains the desired solution, it will, however need to be delayed until it can be combined with other datacentre power upgrades. In the interim, existing power reports will be used to develop a pattern of usage. These will include analysing power consumption bills and point-in-time usage readings, potentially using Smart meters or clamp-on electrical monitors. These will involve manual intervention to record and report on power usage. Though it is recognised that these are sub-optimal measures, they will nonetheless provide correlative data for improved analysis on power consumption to data centre activities. In particular, the movement to improved server utilisation can be independently tracked using such monitoring and thus confirm anticipated reductions.

\section{TANGIBLE ACTIONS}

The ACUPCC signatories agreed to select two or more tangible actions, from a list of seven options, to be completed while their long-term climate action plan is being developed (within two years).

The ACUPCC Implementation Guide also requires the institution to adopt at least two from a list of seven Tangible Actions [2]. Of the recommended actions, only item B (Energy Star procurement Policy) can be considered a significant direct contribution by ICT. Item G (Waste Minimisation) can be facilitated by ICT through both indirect waste reduction and by monitoring other waste reduction efforts. The Guide states:

"B. Adopt an energy-efficient appliance purchasing policy requiring purchase of ENERGY STAR certified products in all areas for which such ratings exist." ([2]; pp. 16)

"G. Participate in the Waste Minimization component of the national RecycleMania competition, and adopt 3 or more associated measures to reduce waste." ([2]; pp. 21)

In response the following initiatives are planned:

\section{A. Procurement procedures}

Objective 3.1: Adopt Electronic Product Environmental Assessment Tool (EPEAT) guidelines into the procurement process for ICT goods and services: Athabasca University (AU) does not currently have a Green Procurement policy. As signatories, $\mathrm{AU}$ will be expected to comply with this recommendation and will therefore need to bring this requirement into policy. Any policy that is formulated will need to include a life-cycle approach to ICT assets with the concomitant whole of life costs, which include environmental externalities.

While policy formulation and adoption are necessary, these measures will be insufficient in ensuring effective implementation and compliance unless they are accompanied by appropriate related procedures. An interesting tool used with respect to this was the Redemtech Sustainable Computing Assessment [4] tool, which provided AU with some valuable indicators and identified areas of weakness within the institution's existing structures and practices (Table 1).

TABLE 1: AU vs. INDUSTRY

\begin{tabular}{|l|c|c|c|}
\hline $\begin{array}{l}\text { Assessment } \\
\text { Category }\end{array}$ & $\begin{array}{l}\text { AU } \\
\text { Score }\end{array}$ & $\begin{array}{l}\text { Industry } \\
\text { Average }\end{array}$ & Comments \\
\hline Productivity & 52 & 32 & \\
\hline Reuse & 68 & 35 & Best Practice \\
\hline Accountability & $\mathbf{4 6}$ & 32 & \\
\hline Energy & 73 & 39 & Mature Programme \\
\hline $\begin{array}{l}\text { Environmental } \\
\text { Social } \\
\text { Responsibility }\end{array}$ & $\mathbf{4 3}$ & 33 & \\
\hline
\end{tabular}

Overall, AU compared well in comparison to the other survey respondents; however, there are significant weaknesses with respect to the introduction of environmentally sustainable procurement practices. The findings included the following comments:

- Audit practices are insufficient;

- Data from IT asset management is ineffectively used;

- Asset management practices are mature;

- Inventory management and control mechanisms are inadequate;

- Formal policy is insufficient to support basic levels of accountability, environmental sustainability, and social responsibility;

- The organization could be better organized to manage off-network security, environmental sustainability, and social responsibility issues.

While these are no more than inferential, the selfassessment does point out areas that will need to be addressed 
across the University to ensure that any policy established will achieve the desired goals and behavioural changes.

An initial action underway is to create a Virtual Contracts Office to help expedite the completion of technology-related contracts. This will involve a team-based approach where contracts are developed in a parallel processing environment with consistent sharing of information and expertise. This approach will significantly reduce time and effort in the development and management of contracts. Moreover, in specific reference to Green ICT, the new organisation will allow changes such as the introduction of EPEAT guidelines to be expedited much more quickly and with a greater level of understanding by all parties. Thus, the introduction of the additional criteria will not impact the process negatively, allowing a more environmentally sensitive approach to be utilised without additional cost.

\section{B. Paper and Print Waste}

A joint organizational print audit was completed with Xerox to determine the total amount of University print related emissions being generated. The total paper used in 2008 was distributed between printed course materials 16,265,000 pages and the office fleet of 2,290,000 pages for a total of 18 , 555,000 pages. The carbon footprint of a single sheet of paper is approximately $0.0042 \mathrm{~kg}$ (or $0.0092 \mathrm{lbs}$ ) of $\mathrm{CO} 2$ [5]. Thus the carbon footprint of AU's printing and copying is approximately $78,000 \mathrm{~kg} / \mathrm{y}$ of $\mathrm{CO} 2$.

The audit produced a range of additional very useful statistics that can be used to help directly address wasteful behaviors. In addition, the statistics will allow AU to benchmark its print operations against similar institutions, in an attempt to identify institutional print drivers. The following three initiatives have been developed with the intent of reducing print related e-Waste by 10 percent annual emissions or $7,800 \mathrm{~kg}$ of $\mathrm{CO}_{2}$ in 2010 .

Objective 3.2: Continue the monitoring and reporting of the print usage statistics in alliance with the Xerox program: The continued monitoring of print usage across the University is essential to providing trend analysis and a baseline to observe changes in behaviour in relation to institutional initiatives. Monitoring and reporting should also be extended to incorporate benchmarking with other post-secondary institutions and comparable organisations, to provide additional awareness of community norms.

Objective 3.3: Reduce print waste through process redesign and automation: It is anticipated that the primary sources of printing need lie in business practices and processes, many of which have become outdated and require automation and digitization. In essence, the print audit can be considered a paper trail to process reengineering.

Objective 3.4: Reduce print waste through a series of initiatives: The results are currently being finalized and will be included in an updated version of the plan. In addition to the above targeted initiatives, a more general set of activities can be employed. These include

- Default of two sided black print setting;

- Increasing print costs to departments in combination with print quotas;

- Sourcing reduced emissions materials; toner, paper and fuser;

- Replacing older units with power management enabled units;

- Elimination of redundant local printers;

- Communication of print based carbon emissions to users to increase awareness.

The above measures are mainly targeted at administrative usage, course materials, which represents the majority of the print requirement, can only be reduced with agreement and active participation from Academic programmes. There has been an ongoing shift to digital provision of course materials since the University adopted its Learning Management System Moodle in 2006, with reductions trending at approximately ten percent per year. It is expected that this will continue, however the savings have not been included in the plan as they are subject to other factors that may not be influenced by this plan.

\section{Climate Action Plan}

The ACUPCC signatories agreed to develop a climate action plan that includes a target date and interim milestones for achieving climate neutrality. Climate neutrality ([2]; pp.34) is defined as "having no net greenhouse gas (GHG) emissions, to be achieved by minimizing GHG emissions as much as possible, and using carbon offsets or other measures to mitigate the remaining emissions" within a minimum scope of boundaries laid out in the ACUPCC Implementation Guide. This is to be achieved through such measures as conservation, renewable energy, and carbon offsets or other measures to mitigate the remaining emissions.

The formulation of an AU-wide Climate Action Plan awaits completion. Therefore, targets are unclear at this time and appropriate levels of action remain to be determined. In the interim, using the information collected in the development of this report, two key initiatives are proposed to be included in the planning process. The first is internally focused and seeks to employ virtualisation technologies with a view to reducing carbon emissions by 30 percent by 2012. Whereas the second initiative is more external and sectorial in approach and its intention is to gain a broad consensus on appropriate conduct across the Alberta Post-Secondary sector and to use this to advance the case for a Green Provincial Datacentre.

This plan has been created with a view to moving Athabasca University (AU) to compliance with the ACUPCC's objective of carbon neutrality. The goal is to reduce ICTrelated CO2 emissions by 30 percent from 2009 levels, while allowing the institution to continue to grow its usage of ICTenabled functionalities.

Over the past year, AU has begun to practice more Green ICT methods. The datacentre in particular has begun to reduce carbon emissions by introducing the following measures:

- Raising the ambient temperature in the datacentre from 18 to 22 degrees centigrade. This has allowed one Air Conditioning Unit to be turned off and eliminate its power consumption; 
- Implementing a central Storage Array Network/Network Attached Storage system which reduces power consumption at individual server level and provides a foundation for server virtualisation;

- Extending the life of all hardware by a minimum of 12 months;

- Replacing all CRT monitors with LCD flat screens;

- Expanding the use of laptops from tower desktops;

- Using power settings on end-point computers;

- Ensuring environmentally sensitive disposal of end of life equipment.

These initiatives are proving worthwhile and have reduced AU's energy related carbon footprint, by an estimated 100,000 $\mathrm{kg} /$ year of $\mathrm{CO} 2$, representing over 12 percent of 2009 emissions. Nonetheless, it is held that there is significant potential to further scale back power usage in the datacentre and in desktop usage through the use of virtualisation technology. While absolute reduction measures are difficult to enforce in a dynamic environment, where ICT is growing in usage as a business support, the ability to achieve the target is firmly held.

Objective 4.1: Reduce ICT related emissions by 30 percent by 2012: To achieve this goal, the university will introduce virtualisation on an ongoing basis. This will take two forms: Server virtualisation and Desktop Virtualisation.

\section{A. Server Virtualisation}

The Green Grid white paper Using Virtualization to Improve Data Center Efficiency [6], used data from a VMWare survey to estimate unconsolidated utilization at between 3 and 10 percent. The white paper went on to recommend categorising servers across Innovation, Production and Mission Critical requirements to ensure workload consistency. It also advocates different levels of consolidation for each category, shown in Table 2.

TABLE 2: GREEN GRID SERVER UTILISATION RATES

\begin{tabular}{|l|c|c|c|c|}
\hline Categories & Innovation & Production & $\begin{array}{c}\text { Mission } \\
\text { Critical }\end{array}$ & Total \\
\hline Server count & 250 & 175 & 75 & 500 \\
\hline Utilization & $3 \%$ & $6 \%$ & $10 \%$ & $5 \%$ \\
\hline $\begin{array}{l}\text { Watts (173 per } \\
\text { server) }\end{array}$ & 43250 & 30725 & 1297.5 & 86500 \\
\hline $\begin{array}{l}\text { Consolidation } \\
\text { Ratio }\end{array}$ & $15: 1$ & $10: 1$ & $5: 1$ & $-10: 1$ \\
\hline $\begin{array}{l}\text { Remaining } \\
\text { Servers }\end{array}$ & 17 & 18 & 15 & 50 \\
\hline $\begin{array}{l}\text { Post- } \\
\text { consolidation } \\
\text { Utilization }\end{array}$ & $50 \%$ & $50 \%$ & $50 \%$ & $50 \%$ \\
\hline $\begin{array}{l}\text { Post- } \\
\text { consolidation } \\
\text { Watts }\end{array}$ & 3910 & 4140 & 3450 & 11500 \\
\hline Energy savings & 39340 & 26135 & 9525 & 75000 \\
\hline
\end{tabular}

The consolidation rates proposed are somewhat below those suggested by both the University of Indiana [7] and Stanford University [8], where upwards of 20:1 ratios were achieved. Nonetheless, the implications for AU are significant. To date,
AU has approximately 60 virtual server instances, yielding a ratio of server instances to physical servers of 1.25:1.

With approximately 240 servers currently deployed, an increase to a $4: 1$ ratio by the end of year three would reduce the server farm to approximately 70 servers. This would reduce the corresponding power requirement by 65 percent; however, this is offset by the growth in servers due to increasing ICT usage, most notably the server requirement for Desktop Virtualisation.

\section{B. Desktop Virtualisation}

The introduction of desktop virtualisation will significantly reduce the power consumption of local end-point devices and allow a reduced hardware specification to substitute for existing desktop devices. A JISC study [9] demonstrated savings of between 80 and 90 percent in power consumption between the use of thin client terminals and full desktop computers.

An active project has completed the pilot phase and is now moving to implement desktop virtualisation. It is anticipated that the technology will be fully operational by autumn 2011 .

The savings from this substitution will not be seen over the next three years, as only approximately 100 of a projected 540 computers will be substituted. This is as a result of the University seeking to prolong the life of still functional units to reduce embedded carbon e-Waste and to reduce overall equipment costs.

Table 3 shows the forecast position of $\mathrm{AU}$ at the end of 2012 inclusive of the growth assumptions identified in the last column. The majority of savings are coming from the impacts of server virtualisation with some additional reduction coming from Desktop Virtualisation. The growth assumptions are based on planned technological developments and anticipated organisational growth. The target of a 30 percent reduction is achievable under the assumptions outlined here, while also allowing flexibility for the institution to grow.

TABLE 3: CARBON EMISSIONS TARGETS FOR ICT RELATED ACTIVITIES 2009 2012

\begin{tabular}{|c|c|c|c|c|c|c|c|}
\hline Category & $\begin{array}{c}\text { Energy } \\
\text { use } \\
(\mathbf{k W h} / \mathbf{y})\end{array}$ & $\begin{array}{c}\text { Category } \\
\mathbf{\%} \mathbf{2 0 1 2}\end{array}$ & $\begin{array}{c}\text { Category } \\
\mathbf{2 0 0 9}\end{array}$ & $\begin{array}{c}\text { CO2 } \\
\text { emissions } \\
(\mathbf{k g} / \mathbf{y}) \\
\mathbf{2 0 1 2}\end{array}$ & $\begin{array}{c}\text { CO2 } \\
\text { emissions } \\
(\mathbf{k g} / \mathbf{y}) \\
\mathbf{2 0 0 9}\end{array}$ & $\begin{array}{c}\text { Emissions } \\
\text { reduction } \\
\text { target } \\
\mathbf{2 0 1 2}\end{array}$ & $\begin{array}{c}\text { Cumulative } \\
\text { Annual } \\
\text { growth rate } \\
\mathbf{2 0 0 9 - 1 2}\end{array}$ \\
\hline HPC & 0 & $0.00 \%$ & $0.00 \%$ & 0 & 0 & & \\
\hline Servers & 478716 & $46.70 \%$ & $66.30 \%$ & 257080 & 545322 & $47 \%$ & $13 \%$ \\
\hline PCs & 273798 & $26.70 \%$ & $18.20 \%$ & 147035 & 149492 & $98 \%$ & $3 \%$ \\
\hline Networks & 103035 & $10.00 \%$ & $6.20 \%$ & 55332 & 50618 & $109 \%$ & $3 \%$ \\
\hline Telephony & 40208 & $3.90 \%$ & $1.10 \%$ & 21593 & 9023 & $239 \%$ & $3 \%$ \\
\hline Imaging & 121165 & $11.80 \%$ & $7.90 \%$ & 65068 & 65068 & $100 \%$ & $0 \%$ \\
\hline AV & 9079 & $0.90 \%$ & $0.40 \%$ & 4876 & 2960 & $165 \%$ & $20 \%$ \\
\hline TOTAL & $\mathbf{1 0 2 6 0 0 2}$ & $\mathbf{1 0 0 . 0 0 \%}$ & $\mathbf{1 0 0 . 0 0 \%}$ & $\mathbf{5 5 0 9 8 3}$ & $\mathbf{8 2 2 4 8 3}$ & $\mathbf{6 7 \%}$ & \\
\hline
\end{tabular}

Objective 4.2: Adopt the EU Code of Conduct for datacentre operations: The Post-Secondary sector IT organisation Alberta Association in Higher Education for Information Technology (AAHEIT) has begun to look at the possibility of a provincial green datacentre. There is a serious interest in the concept, particularly as the availability of Disaster Recover Planning (DRP) sites is critically lacking. 
There are many hurdles between desired concept and actualised physical structure. However, there is a growing belief that it may be possible. It is held that such a centre is critical to the optimising of emissions control of ICT activities in the sector, as well as to their efficient and economic operation.

The EU Code of Conduct on Data Centres Energy Efficiency (EUC) [10] provides a basis for establishing such a centre through general principles, governance structures, working practices and practical action. Given the nature of its construction, the EUC provides a framework for other consortia to follow, being sufficiently flexible and adaptable to different contexts.

It is also written with the intention of adoption in multiorganisational environments where decision making is consensual. The EUC therefore provides an essential scaffold allowing the concept to be discussed in a more coherent, consistent and objective manner. AU's adoption will provide an initial starting point, in having one institution piloting this adoption and thus able to provide real usage information to suggest whatever adaptations may be necessary within the Alberta post-secondary context.

\section{REPORTING REQUIREMENTS}

The ACUPCC signatory institutions also commit to make their institutional structure, greenhouse gas inventory, climate action plan, and progress reports publicly available by providing them to AASHE for posting and dissemination.

\section{A. Plan Format, Methodology and Emissions Calculation Tool}

Athabasca University's plan will follow the format as outlined in the ACUPCC Instructions for Submitting a Greenhouse Gas Report [11]. The Consolidation methodology used will be the Operational Control Approach [12]. This method accounts for Greenhouse Gas (GHG) emissions from the operational perspective, where the institution has the authority to implement effective operational policies and controls. Regarding scope of emissions recording, the plan will focus on those designated by the Greenhouse Gas Protocol [12] as Scope 2 and 3 Emissions. Where Scope 2 Emissions deal with emissions from purchased electricity and Scope 3 Emissions, include indirect emissions not controlled directly by the organization but which are driven by its consumption rates, such as material transportation, travel and waste disposal.

As mentioned in Section III, the JISC emissions calculator will be used to measure ICT activities [3]. To comply with ACUPCC requirements, the results from the JISC tool will be subsequently aggregated into the campus-wide analysis using the ACUPCC recommended Campus Carbon Calculator [13]. This two-tier monitoring and reporting methodology is recommended on an ongoing basis. The tool is comprehensive, incorporating all aspects of an institution's activities, and provides a consistent methodology across the sector.

Objective 5.1: Develop reporting and forecasting structure to provide projections on ICT $\mathrm{CO}_{2}$ emissions: Through the use of the JISC emissions calculator and similar tools, the
University will be able to effectively develop $\mathrm{CO}_{2}$ emissions forecasts when considering its annual business planning activities, and when valuating options regarding green-related choices. The projections used in this report to substantiate the 30 percent reduction target used the JISC tool in this manner. Nonetheless, it will be necessary to improve the fit of the JISC tool to the AU environment. Therefore, the following sub-goal is recommended.

Objective 5.2: Develop the JISC Carbon Footprint Tool to better approximate the AU environment and its integration into the Campus Carbon Calculator: The JISC tool will need to be customised to match the University's actual operating position over time. As the inventory of equipment becomes more extensively mapped, the categories within the tool can be made to closer approximate the actual conditions within the institution. The aggregation into the institution's instance of the Campus Carbon Calculator should be automated to ensure accuracy and timeliness.

\section{CONCLUSION}

The main hurdle to Greening the ICT infrastructure of any organization is not the technology, nor indeed the organizational resistance; it is the overloaded agenda of ICT units themselves. The constant escalation of demands to improve functionality, interoperability, integration, and availability, place such a demand on the intellectual and energy reserves of the managers and professionals in these units, that the adoption of additional activities, no matter how well intentioned or planned, becomes almost impossible to achieve. At AU we have moved our green ICT initiative forward, not within a coherent program framework, but in a more organic process. The critical enabler to this is the understanding of the emissions portfolio. Through the baselining of activity emissions the organization can develop a schedule from which greening actions can be weaved into operational plans. Effort can be substantiated by reward, and actions can be made that provide improvement to the organization while reducing $\mathrm{CO} 2$ emissions.

The purpose of this paper is to introduce Athabasca University's plan which is an attempt to provide a schedule to act as a reference guide for the ICT management team to consider when making routine, tactical and strategic decisions regarding the acquisition and implementation of information technology. But perhaps, of more importance it will help create an environment that will allow the growth of a green culture to emerge without forcing divisionary choices to be made that would forestall its progress.

\section{REFERENCES}

[1] ACUPCC (no date). University and College Presidents' Climate Change Statement of Action for Canada. Retrieved on April 18, 2011 from http://www.climatechangeaction.ca/

[2] Dautremont-Smith, Julian. (2009). Implementation Guide, Information and resources for Participating Institutions (September 2007). Tangible Actions. ACUPCC Retrieved on April 18, 2011 from http://www.presidentsclimatecommitment.org/pdf/ACUPCC IG Final.p df 
[3] SusteIT (no date). Joint Information System Committee, Sustainable Information technology in Tertiary Education, JICT Carbon Footprin Tool. Retrieved on April 18, 2011 from http://www.susteit.org.uk/files/category.php?catID=4

[4] Redemtech (2010). Sustainable Computing Assessment. Retrieved on April 18, 2011 from http://www.redemtech.com/assessment/

[5] Standard Carbon (2008). Do You Really Need to Print That? The Carbon Footprint of Copy Paper. Retrieved on April 18, 2011 from http://www.standardcarbon.com/2008/do-you-really-need-to-print-thatthe-carbon-footprint-of-copy-paper/

[6] Brey, T. \& Lamers, L. (2009). Using Virtualization to Improve Data Center Efficiency. Working Paper \#19. Green Grid - Operations. Retrieved on April 18, 2011 from http://www.thegreengrid.org/en/sitecore/content/Global/Content/whitepapers/Using-Virtualization-to-Improve-Data-Center-Efficiency.aspx

[7] Cromwell, Dennis J. (2009). Making IT a Key Part of the Campu Sustainability Effort. Educause Live Retrieved on April 18, 2011 from http://www.educause.edu/Resources/MakingITaKeyPartoftheCam pusSus/173377

[8] Dickerson, Joyce. (2009). From Desktops to Data Centers: Sustainable IT at Stanford. Educause Live Retrieved on April 18, 2011 from http://www.educause.edu/Resources/FromDesktopstoDataCentersSusta/ 169459

[9] JISC (2009). Thin-client Saves Energy Costs: A case study in Green ICT. Retrieved on April 18, 2011 from http://www.jisc.ac.uk/publications/documents/greenictqueenmargaret.as pX

[10] European Commission (2008). Code of Conduct on Data Centres Energy Efficiency. Version 1.0. Retrieved on April 18, 2011 from http://re.jrc.ec.europa.eu/energyefficiency/pdf/CoC\%20data\%20centres \%20nov2008/CoC\%20DC\%20v\%201.0\%20FINAL.pdf

[11] ACUPCC (no date). Reporting System Instructions for Submitting a Greenhouse Gas Report. ACUPCC. Retrieved on April 18, 2011 from http://acupcc.aashe.org/instructions-ghg-report.php

[12] WRI \& WBCSD (2004). A Corporate Accounting and Reporting Standard (revised Edition). Chapter 3: Setting Organizational Boundaries. GHG Protocol. Retrieved on April 18, 2011 from http://www.ghgprotocol.org/files/ghgp/public/ghg-protocol-revised.pdf

[13] Clean Air, Cool Planet (2008). Campus Carbon Calculator. Retrieved April 18, 2011 from http://www.cleanair-coolplanet.org/toolkit/invcalculator.php

Brian Stewart is Vice President and Chief Information Officer at Athabasca University. Brian's role is to provide strategic leadership to the application of Information and communications technology (ICT) to the activities of the University. Brian is charged with identifying and resourcing appropriate technologies to improve administrative effectiveness and efficiency; to assis the academic community's use of ICT to develop programs which improve students' learning and success; and to facilitate the research and development of world class e-learning initiatives. He is chair of the Association of Alberta for Higher Education Information Technology, and is chair of the Alberta Post secondary Application System CIO's Group. Brian also has published and presented on cloud computing, Green ICT and the use of ICT in printing and education.

Anshuman Khare is a professor in Operations Management at Athabasca University, Canada. He is an Alexander von Humboldt Fellow. His research focuses on environmental regulation impacts on the automobile industry and its supply chain. He is also a former Monbusho Scholar, having completed a postdoctoral assignment at Ryukoku University in Kyoto, Japan. He has published six books and a number of research papers on a wide range of topics, including Just-in-Time; supply chain management; sustainable developmen related to public policy; regulations and strategic developments resulting from climate change regulations and initiatives; ecopreneurship; sustainable cities corporate social responsibility; and the impact of environmental/climate change regulations on technology, innovation and corporate strategy. 